\section{Diabetic retinopathy in an adolescent with Prader-Labhart-Willi syndrome}

The Prader-Labhart-Willi syndrome is characterized by perinatal muscular hypotonia, short stature, mental retardation, hypogonadism (cryptorchidism in males), and severe, progressive obesity. Another feature of this syndrome is the development of glucose intolerance, followed by overt juvenile diabetes mellitus of the maturity onset type (Illig, Ischymi, and Vischer, 1974). Esotropia and amblyopia are also common (Dunn, 1968). The aetiology of this syndrome is not clear, but the existence of a hypothalamic lesion is assumed (Hetherington and Ranson, 1942; Larsson, 1954).

The appearance of diabetic retinopathy in long-standing diabetes is well known but its association with this syndrome has not been reported.

\section{Case report}

A male patient was first seen in our clinic at the age of 13, when he presented all the classical characteristics of the Prader-Labhart-Willi syndrome. Family history of diabetes mellitus was negative. At the age of 16 years the first clinical signs of diabetes mellitus appeared. It was controlled by a low-carbohydrate diet and a hypoglycaemic agent up to the age of 18 years, when insulin treatment was started. At the age of 22 the patient successfully reduced his weight from $140 \mathrm{~kg}$ to $96 \mathrm{~kg}$. This weight reduction was associated with an improvement in the clinical diabetes so that the insulin could be stopped. He is now controlled on a low-carbohydrate diet alone.

Ophthalmological findings. At age 13 years: vision, right eye $-10 \cdot 0=1 / 30$; left eye $-2 \cdot 0=6 / 12$. Esotropia of the right eye. Constant nystagmus in both eyes, increasing on fixation. Irides light blue. Albinotic fundi. No microaneurysms detected.

When he was 22 we first found a few microaneurysms between the papilla and the macula in the left eye. Visual acuity and the nystagmus were unchanged. The right fundus showed a slightly myopic conus and was albinotic. One microaneurysm was seen adjacent to the macula. 2 months later the fundus of the right eye was unchanged. The number of microaneurysms in the left eye had increased and a vessel anomaly was detected in the upper temporal part, near the macula. Attempts to perform fluorescein angiography of the fundi were unsuccessful because of the nystagmus and lack of co-operation by the patient.

\section{Discussion}

Diabetic retinopathy has not been previously described in the Prader-Labhart-Willi syndrome, despite the occurrence of diabetes mellitus in many of the older patients. Most of the reported cases of the syndrome have been younger than our patient so that the finding of microaneurysms was not to be expected.

The exact sequence of changes in the development of diabetic retinopathy is as yet unknown (Osterby, 1974). The modern concept of the disease is that of a widespread microangiopathy which leads to the first signs of background retinopathy. Patients with juvenile diabetes rarely show retinopathy in the first 5 years of the disease, but after 10 years the frequency increases rapidly, and after 25 years of diabetes $90 \%$ of patients have developed retinopathy. Background retinopathy has a variable progression and regression, but about $40-50 \%$ show deterioration, though this is slower in younger patients than in the older ones (Kornerup, 1955; Caird, Pirie, and Ramsell, 1969; Okun, Johnston, and Boniuk, 1971).

Among 150 cases of juvenile diabetes in the age group of 10-20 years and a duration of diabetes from 2 to 14 years which were seen in our clinic, retinopathy was found in only 7 patients, all of them after 7 years of diabetes (Savir, 1974).

In the case presented here, the first microaneurysms were found 6 years after the onset of diabetes. These increased rapidly in number within the next 2 months and a vessel anomaly was seen. This time interval is short for the appearance of retinopathy, but recent reports on the electron microscopical examination of capillaries indicate that in juvenile diabetes specific changes can be found in the basement membrane about 3 to 5 years after the onset of clinical diabetes (Osterby, 1974; Kilo, Vogler, and Williamson, 1972).

The distribution, the rapid increase in number, and the appearance of vessel changes, all support the view that the retinopathy is truly diabetic in origin.

\section{Summary}

In a case of Prader-Labhart-Willi syndrome diabetes mellitus of the maturity-onset type appeared at the age of 16 years and diabetic retinopathy was first observed at 22 years. The patient has albinotic and myopic fundi, nystagmus, esotropia, and amblyopia of the right eye. The number of microaneurysms in the fundi increased markedly during a follow-up period of 6 months.

\section{REFERENCES}

Caird, F. I., Pirie, A., and Ramsell, T. G. (1969). Diabetes and the Eye. Blackwell Scientific Publications, Oxford.

Dunn, H. G. (1968). The Prader-Labhart-Willi syndrome. Review of the literature and report of 9 cases. Acta Paediatrica Scandinavica, 57, Suppl. 186. 
Hetherington, A. W., and Ranson, S. W. (1942). Spontaneous activity and food intake of rats with hypothalamic lesions. American Fournal of Physiology, 136, 609.

Illig, R., Ischymi, A., and Vischer, D. (1974). The Various Faces of Diabetes in fuveniles. Proceedings of the 2nd International Beilinson Symposium, October 1972. Ed. by Z. Laron and M. Karp. Karger, Basel.

Kilo, C., Vogler, N., and Williamson, J. R. (1972). Muscle capillary basement membrane changes related to aging and to diabetes mellitus. Diabetes, 21, 881.

Kornerup, T. (1955). Studies in diabetic retinopathy. An investigation of 1,000 cases of diabetes. Acta Medica Scandinavica, 153, 81.

Larsson, S. (1954). On the hypothalamic organisation of the nervous mechanism regulating food intake. Acta Physiologica Scandinavica, 32, Suppl. 115.

Okun, E., Johnston, G. P., and Boniuk, I. (1971). Management of Diabetic Retinopathy. Mosby, St. Louis.

Osterby, R. (1974). Electron microscopy of vascular changes in juvenile diabetes. In The Various Faces of Diabetes in Fuveniles. Proceedings of the 2nd International Beilinson Symposium, October 1972. Ed. by Z. Laron and M. Karp. Karger, Basel.

Savir, H. (1974). Vascular changes in the eyes of young diabetics. In The Various Faces of Diabetes in Fuveniles. Proceedings of the 2nd International Beilinson Symposium, October $1972 . \quad \mathrm{Ed}$. by Z. Laron and $M$. Karp. Karger, Basle.

A. SAVIR, Z. Dickerman, M. KARP, and Z. LARON* From the Department of Ophthalmology and The Institute of Paediatric and Adolescent Endocrinology, Beilinson Medical Centre, Petah Tiqva, Sackler School of Medicine, Tel Aviv University, Israel.

*Correspondence to Professor Z. Laron, Institute of Paediatric and Adolescent Endocrinology, Beilinson Hospital, Petah Tiqva, Israel.

\section{'Moyamoya' associated with peripheral vascular occlusive disease}

Moyamoya is a condition characterized by multiple occlusions of the cerebral circulation with an unusual net-like system of collaterals. The majority of patients previously reported have been Japanese.

This report is of an Australian boy, and is unique in describing the previously unreported occurrence of moyamoya with peripheral vascular occlusions.

\section{Case report}

The patient is a boy of Anglo-Saxon origin who presented at the age of 13 years with an acute hemiplegia. At the age of 6 months, he developed chilblains on his hands. These have recurred with increasing severity in cold weather, resulting in small areas of gangrene on his hands and feet and loss of tissue from the tips of his ears (Fig. 1). Because of the severity of the chilblains, he was first seen at the Royal Children's Hospital, aged 2 years. At regular examinations throughout his life he was noted to have good peripheral pulses and the only

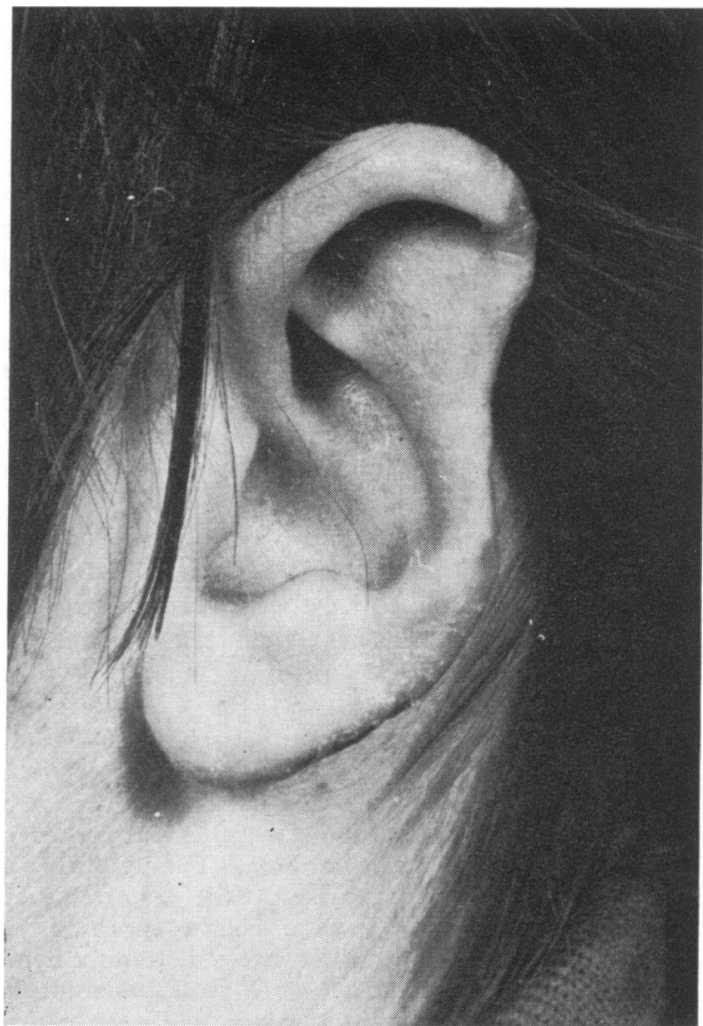

Fig. 1.-Loss of tissue from ear.

satisfactory management was avoidance of cold. At 6 years of age he was seen because of unsteadiness of gait and subsequent chorea, followed by slurred speech and emotional lability. His chorea and slurred speech persisted for 6 months but emotional lability has continued to the present time.

He was first seen by the author at 13 years of age when he presented with an acute left hemiplegia. On examination he was disorientated with a profound left hemiplegia. Blood pressure was $130 / 80 \mathrm{mmHg}$ and all peripheral pulses were easily palpable. He was discharged after 3 weeks, his disabilities being a mild left hemiparesis, squeaky voice, and hyperactivity. When reviewed 12 months later he showed minimal weakness of his left arm and leg, further scarring, and tissue loss from digits and ears, and for the first time a very small area of gangrene at the tip of his nose.

\section{Investigations.}

Angiography. 2 days after onset of hemiparesis carotid angiography revealed narrowing of the supraclinoid portions of both internal carotid arteries, occlusion of the anterior and middle cerebral vessels just distal to their origins from the internal carotid arteries, and a vast network of fine collateral vessels in the region 